\title{
The Bactericidal Action of Streptomycin on Staphylococcus aureus and Some Accompanying Biochemical Changes
}

\author{
By R. HANCOCK \\ Department of Bacteriology, University of Manchester
}

(Received I March 1960)

\begin{abstract}
SUMMARY
Some factors which affect the killing by streptomycin of Staphylococcus aureus in growing cultures have been investigated. In short-term experiments, streptomycin is not bactericidal under conditions in which growth of the organisms cannot occur (low temperature, absence of nitrogen source, presence of growth-inhibitory concentrations of chloramphenicol). The rate of killing of organisms growing anaerobically is considerably lower than that of organisms growing aerobically. Streptidine can partially reverse the growth inhibitory effect of streptomycin. During the period in which growth becomes inhibited by streptomycin, the rates of incorporation of ${ }^{14} \mathrm{C}$-labelled precursors into the major cell constituents, and of synthesis of nucleic acids, are reduced simultaneously, and no large changes occur in the total quantities of amino acids or $260 \mathrm{~m} \mu$-absorbing substances in the metabolic pool. During this period the rate of metabolism of glucose via the Embden-Meyerhof pathway is decreased, but there is no change in the proportion of the total glucose oxidized which is metabolized via a $C_{1}$-preferential oxidation. The $Q_{o_{2}}$ value for oxidation of glucose by organisms harvested when inhibition of growth by streptomycin is first detectable is lower, by about $20 \%$, than that of normal organisms, and falls to c. $\mathbf{B 0} \%$ of normal when growth is fully inhibited. At this time the $\mathbf{Q}_{\mathbf{O}_{2}}$ values for oxidation of glycerol, lactate and formate are also reduced, by $40-80 \%$. These effects appear to be specific to organisms whose growth is inhibited by streptomycin.
\end{abstract}

\section{INTRODUCTION}

Many investigations have shown that streptomycin can affect numerous metabolic reactions in streptomycin-sensitive bacteria, both in growing and in non-growing organisms. It is not practicable to review all these observations here; early results have been discussed by Henry \& Hobby (1949), and a very valuable discussion of more recent work has been given by Lightbown (1957).

A number of workers (Barkulis, 1953; Rosanoff \& Sevag, 1953; Umbreit, 1953) have shown that, in non-growing organisms, streptomycin can inhibit certain reactions concerned in the metabolism of pyruvate in Escherichia coli, although the relationships between these inhibitory effects and the inhibition of growth has not been investigated. Hypotheses based on these and other observations have been discussed in detail by Lightbown (1957), particularly in relation to the antagonism between streptomycin and certain substituted quinoline $\boldsymbol{N}$-oxides which can inhibit a reaction in the cytochrome system (Lightbown \& Jackson, 1956). The increased resistance to streptomycin which is shown by facultatively anaerobic organisms when growing under low oxygen tensions (Bondi, Dietz \& Spaulding, 
1946; May, Voureka \& Fleming, 1947; Lightbown, 1954, 1957) or in the presence of certain inhibitors of the cytochrome system (Lightbown, 1957) suggests that the growth-inhibitory action of streptomycin may depend on the operation of the cytochrome system. Lightbown (1957) has suggested that these phenomena may be due to the interrelationships, such as the Pasteur effect, between aerobic respiratory processes and other reactions of intermediate metabolism. An alternative hypothesis which would be compatible with these observations is that the access of streptomycin to its site of action is dependent on the presence of oxygen or on some aerobic metabolic process.

No published studies describing inhibitory effects of streptomycin on metabolic reactions have established that inhibition of the affected reactions is the primary cause of loss of viability of the organisms. Many investigations have been concerned with effects of streptomycin on suspensions of non-growing organisms. However, it has been shown (Wasserman, Lessner \& West, 1954; Lightbown,1957) that organisms from exponentially growing cultures are much more rapidly killed by streptomycin than are non-growing organisms. It is possible therefore that the processes which lead to loss of viability in the presence of streptomycin do not occur in non-growing organisms, and it may be more profitable to search for effects of streptomycin using growing organisms under conditions of maximum sensitivity to streptomycin. It is also possible that the properties of metabolic systems in non-growing organisms may differ both qualitatively and quantitatively from those ingrowing organisms; such a difference in the properties of the acetate-oxidizing system of Escherichia coli, and in its sensitivity to inhibition by streptomycin, has been shown by Vignais \& Vignais (1954)

This paper describes experiments designed to determine the conditions under which Staphylococcus aureus shows greatest sensitivity to streptomycin, as a basis for investigations of biochemical changes during the inhibition of growth by streptomycin. Some factors which affect the activity of streptomycin have also been investigated, and initial attempts to search for early biochemical changes during the period of inhibition of growth are described. Some of these findings have been published in abstract form (Hancock, 1960).

\section{METHODS}

Organism, growth and harvesting. Throughout this work Staphylococcus aureus strain Duncan (Gale \& Taylor, 1947) was grown in the peptone-glucose medium (PG) described previously (Park \& Hancock, 1960), adjusted accurately to a pH value of 7.2. In early experiments difficulties were encountered due to variations in the effects of streptomycin in different batches of media, which sometimes made comparisons between different experiments difficult. These variations occurred in spite of care in controlling conditions of sterilization and final $\mathrm{pH}$ value, and eventually all the experiments described here were carried out using medium drawn from two large batches, which were tested to ensure that the response of the organism to streptomycin was identical in each batch. In some experiments the composition of the medium was changed slightly: when radioactive glucose was used, the final glucose concentration in the growth medium was $0.02 \%(w / v)$; when radioactive phosphate was used, the phosphate in the medium was partially replaced by 2 -amino- 
2-hydroxymethyl-propane-1: 3 diol, as described by Park \& Hancock (1960). These changes in the medium did not result in any change in the response of the organism to streptomycin.

For counting numbers of viable organisms, the normal PG medium, solidified by addition of $2 \%(w / v)$ agar (New Zealand), was used.

All experiments were performed using cultures growing at $37^{\circ}$ in Erlenmeyer flasks shaken in a constant-temperature water bath; the prewarmed medium was inoculated with $10 \%(\mathrm{v} / \mathrm{v})$ of an overnight culture grown in the same way. To grow organisms under anaerobic conditions, similar flasks were fitted with a bung with a tube and tap, through which the flask was twice evacuated and flushed with nitrogen. For experiments on the growth of cultures under low oxygen tensions, organisms were grown in test tubes $(10 \mathrm{~cm} . \times 1 \mathrm{~cm}$.) which fitted the Unicam SP. 600 spectrophotometer; these tubes were incubated in an air incubator at $37^{\circ}$. The tubes contained $5 \mathrm{ml}$. of medium; before use they were heated in a boiling water bath for $5 \mathrm{~min}$. to remove dissolved air, and a layer of sterile liquid paraffin was placed on the surface. Before measuring the optical density of such cultures, the organisms were resuspended by gentle pipetting with a Pasteur pipette, care being taken to introduce no air through the layer of paraffin.

The extent of growth was followed by determining the optical density of cultures at $700 \mathrm{~m} \mu$, using the Unicam SP. 600 spectrophotometer. When streptomycin was added to a portion of a culture, this was done when the optical density was between 0.30 and 0.40 .

Organisms were harvested on 'Oxoid' membrane filters using either $6 \mathrm{~cm}$. diameter filters in a 'Quickfit' all-glass assembly or $8 \mathrm{~cm}$. diameter filters in an assembly made in this laboratory. The organisms were washed on the membrane filter with ice-cold water. In most cases they were then resuspended, either in ice-cold water for the preparation of cell suspensions for fractionation or metabolic experiments, or in prewarmed growth medium when subsequent growth was to be followed, by covering the filter with suspending medium and gently rubbing off the organisms with a fine glass rod.

Sensitivity tests and counting of viable organisms. The minimum inhibitory concentrations of streptomycin and related compounds were determined in tubes containing $5 \mathrm{ml}$. of medium; the tubes were inoculated with 1 drop of a shaken culture which had grown for $\mathbf{2 4} \mathrm{hr}$. and was in the stationary phase of growth, and were incubated for $16 \mathrm{hr}$. at $37^{\circ}$.

For counting numbers of viable organisms, successive tenfold dilutions were made of samples of a culture, using growth medium as diluent. Three replicate samples, taken from each of four successive dilutions, were placed on the surface of dried agar plates using a calibrated dropper according to Miles \& Misra (1938). Colonies were counted after incubation of the plates at $37^{\circ}$ for $24 \mathrm{hr}$. under aerobic conditions or after $48 \mathrm{hr}$. under anaerobic conditions. Colony counts were only recorded from those plates on which the samples had contained between 10 and 100 viable organisms. In the values presented here the extreme values always differed by less than $10 \%$ from the mean value. The number of organisms in a culture which were resistant to streptomycin was determined similarly, by plating on agar containing streptomycin at the required concentration. In the experiments described in Fig. 2, diluted samples were spread over the whole surface of plates, using a glass spreader. 
In determinations of numbers of viable organisms under the conditions used here, no difficulties were encountered due to irregular effects of dilution or to nonreproducibility in replicate samples, such as Barer (1951) found with Bacterium lactis aerogenes.

Fractionation of organisms. To prepare hot-water extracts of organisms, the membrane filter covered with organisms was rapidly transferred, usually within $3 \mathrm{~min}$. of harvesting, to a beaker of boiling water and immersed for $10 \mathrm{~min}$. The filter was then removed and rinsed with water; the aqueous extract was centrifuged at $3000 \mathrm{~g}$ for $15 \mathrm{~min}$. to remove cell debris and the supernatant solution was freezedried. The cold trichloracetic acid (TCA)-soluble fraction was prepared by pipetting a sample of a suspension of organisms, washed off a membrane filter as described above, into an equal volume of $10 \%(\mathrm{w} / \mathrm{v})$ TCA. After $30 \mathrm{~min}$. at $5^{\circ}$, the suspension was centrifuged at $3000 \mathrm{~g}$ for 15 min., the pellet was resuspended in $5 \%(w / v)$ TCA and again centrifuged, and the supernatant solutions were combined. The compounds in this fraction were separated using the fractionation procedure $\mathbf{A}$ of Umbreit, Burris \& Stauffer (1951). In one experiment the fractionation scheme used by Umbreit (1953) was used.

Samples (2-10 ml.) taken from cultures containing ${ }^{14} \mathrm{C}$-amino acids, ${ }^{14} \mathrm{C}$-glucose or ${ }^{32} \mathrm{P}$-orthophosphate were pipetted rapidly into an equal volume of ice-cold $10 \%(w / v)$ TCA; the cold-TCA-insoluble residue was then fractionated by the procedure of Park \& Hancock (1960). Total radioactivity in the organisms was determined using organisms harvested rapidly on a $2 \mathrm{~cm}$. diameter membrane filter; the filter was washed twice with $2 \mathrm{ml}$. quantities of ice-cold water and mounted on a planchette for radioactivity determinations. The difference between the total radioactivity and that in the cold-TCA-insoluble fraction gave the radioactivity in the cold-TCA-soluble fraction. The abbreviation cpm has been used for counts per minute.

With the exception of $\mathrm{Ba}^{14} \mathrm{CO}_{3}$, radioactive samples were mounted on planchettes under conditions where self absorption was less than $5 \%$, as described elsewhere (Park \& Hancock, 1960). Precipitates of $\mathrm{Ba}^{14} \mathrm{CO}_{3}$ were suspended in $50 \%(\mathrm{v} / \mathrm{v})$ aqueous ethanol and pipetted on to similar planchettes. In experiments in which the production of ${ }^{14} \mathrm{CO}_{2}$ from ${ }^{1-14} \mathrm{C},{ }^{6-14} \mathrm{C}$ and generally- ${ }^{14} \mathrm{C}$-labelled glucose was measured in three identical cultures, it was assumed that the total amount of $\mathrm{CO}_{2}$ evolved in each culture was the same. Only the ratios of the specific activities of the ${ }^{14} \mathrm{CO}_{2}$ produced in the three cultures were required, and not absolute values, and the further assumption was made that the weights of $\mathrm{Ba}^{14} \mathrm{CO}_{3}$ on each of the three planchettes from any single experiment were identical; corrections for self absorption were not made and the results of such experiments are expressed as ratios of the observed radioactivity on each planchette.

For estimations of nucleic acids, samples $(10 \mathrm{ml}$.) of a culture were taken into perchloric acid (final concentration $0 \cdot 25 \mathrm{~N}$ ); subsequent treatment and estimation of deoxyribonucleic acid (DNA) were by the method of Burton (1956). Total nucleic acid was estimated by measuring absorption at $260 \mathrm{~m} \mu$, using the same extract as that used for DNA estimation. The results of nucleic acid estimations have been expressed in terms of amounts of nucleic acid phosphorus, using the conversion factor given by Burton (1956) for DNA and that of Gale \& Folkes (1953) for total nucleic acid (TNA). 
Manometric techniques. Warburg manometer flasks contained $300 \mu$ moles $\mathbf{K}$ phosphate buffer pH 7.2 and c. $5 \mathrm{mg}$. dry weight of organisms in a volume of $2.0 \mathrm{ml}$. $1.0 \mathrm{ml}$. of a solution $(0.01 \mathrm{M})$ of the appropriate substrate was added from the side arm to start the reaction. The gas phase was air and the temperature $37^{\circ}$. To measure oxygen uptake, $\mathbf{0 . 2} \mathrm{ml}$. of $\mathbf{4 0} \%$ (w/v) $\mathrm{CO}_{2}$-free $\mathrm{KOH}$ was placed in the centre well; a folded filter paper was added, except when production of ${ }^{14} \mathrm{CO}_{2}$ was being measured. The rate of gas uptake was followed at $5 \mathrm{~min}$. intervals for a $30 \mathrm{~min}$. period, over which it was linear; experimental values were corrected for the rate of endogenous gas exchange in the absence of substrate. All determinations were carried out in duplicate. When ${ }^{14} \mathrm{CO}_{2}$ was to be collected, $0.5 \mathrm{ml}$. of $25 \%$ (w/v) TCA was added from a second side bulb to terminate metabolism, and the flask was shaken for $1 \mathrm{hr}$. to liberate dissolved $\mathrm{CO}_{2}$. The contents of the centre well were removed with a Pasteur pipette, and the well was rinsed with $0.2 \mathrm{ml} . \mathrm{H}_{2} \mathrm{O}$; the combined solutions were transferred to a centrifuge tube and $\mathrm{BaCO}_{3}$ was precipitated by addition of $2 \mathrm{ml}$. of $1 \%(\mathrm{w} / \mathrm{v})$ barium acetate and $2 \mathrm{ml}$. of $95 \%(\mathrm{v} / \mathrm{v})$ ethanol. After centrifuging $\left(3000 \mathrm{~g}, \mathbf{3 0} \mathrm{min}\right.$.) the $\mathrm{BaCO}_{3}$ was washed by resuspension in $95 \%(\mathrm{v} / \mathrm{v})$ ethanol followed by a similar centrifugation.

All substrates used were of analytical reagent grade; solutions of acidic substrates were neutralized with KOH before use.

Streptomycin and related compounds. The following preparations were used in these experiments: streptomycin sulphate (Glaxo), batch 2736, 740 units/mg.; dihydrostreptomycin sulphate (Glaxo), Batch 5562, 745 units/mg.; mannosidostreptomycin sulphate (L 484249-1-17) and streptidine sulphate (L 496386-1-4), both from Merck, Sharpe and Dohme Research Laboratories, New Jersey, U.S.A.; and streptomycinic acid sulphate (The Distillers Co. (Biochemicals) Ltd, Speke, Liverpool).

Concentrations of these compounds are expressed in terms of weights of the sulphates. Solutions in distilled water were prepared freshly each week and stored in the frozen state; solutions of streptidine and streptomycinic acid were adjusted to $\mathrm{pH} 7 \cdot 0$ before use.

Isotopic compounds. Generally-14 $\mathrm{C}$-labelled amino acids, ${ }^{1-14} \mathrm{C}, 6-{ }^{14} \mathrm{C}$ and generally${ }^{14} \mathrm{C}$-labelled glucose, and ${ }^{32} \mathrm{P}$-orthophosphate, were obtained from the Radiochemical Centre, Amersham. ${ }^{14} \mathrm{C}$-Glucose and ${ }^{32} \mathrm{P}$-orthophosphate were added to the growth medium to give final specific activities of $0.025 \mu \mathrm{c} / \mu \mathrm{mole}$ and $0.1 \mu \mathrm{c} / \mu \mathrm{mole}$, respectively, and ${ }^{14} \mathrm{C}$-amino acids to give a final concentration of $0 \cdot 2 \mu \mathrm{c} / \mathrm{ml}$.

Amino acids were estimated by the procedure of Cocking \& Yemm (1955), slightly modified as described by Park \& Hancock (1960).

Inorganic phosphate was determined by the method of Fiske \& SubbaRow (1925), using one-tenth of the recommended volumes of sample and reagents.

Dry weights of washed organisms were determined after drying duplicate samples for $8 \mathrm{hr}$. at $105^{\circ}$ in an air oven.

\section{RESULTS}

Minimum inhibitory concentrations of streptomycin and related compounds. The minimum inhibitory concentrations of streptomycin and some related compounds against this strain of Staphylococcus aureus, determined by a conventional technique after incubation for $16 \mathrm{hr}$, are given in Fig. 1. Counts of colony-forming organisms in samples taken from those tubes which showed no growth indicated that, under these conditions, streptomycin has a bactericidal, and not only a bacteriostatic, 
effect (Table 1). Dihydrostreptomycin has the same activity as streptomycin in such a test, and mannosidostreptomycin is less active; such relative activities of these three derivatives are frequently found (Waksman, 1949).

Table 1. Bactericidal action of streptomycin in cultures used to determine minimum inhibitory concentrations

Samples taken from an experiment identical with that in Fig. 1.

\begin{tabular}{|c|c|c|}
\hline \multirow{2}{*}{$\begin{array}{l}\text { Streptomycin } \\
\text { sulphate } \\
\text { concentration } \\
(\mu \mathrm{g} . / \mathrm{ml} .)\end{array}$} & \multicolumn{2}{|c|}{ Viable organisms $/ \mathrm{ml}$. } \\
\hline & Initial & After $16 \mathrm{hr}$. \\
\hline 8 & $2.1 \times 10^{5}$ & $1.8 \times 10^{5}$ \\
\hline 10 & $2 \cdot 1 \times 10^{5}$ & $2.2 \times 10^{3}$ \\
\hline 12 & $2 \cdot 1 \times 10^{5}$ & $<1 \times 10^{2}$ \\
\hline
\end{tabular}

When similar tubes were incubated in nitrogen in a McIntosh \& Fildes jar, considerably higher concentrations of streptomycin were necessary to inhibit growth (Fig. 1).

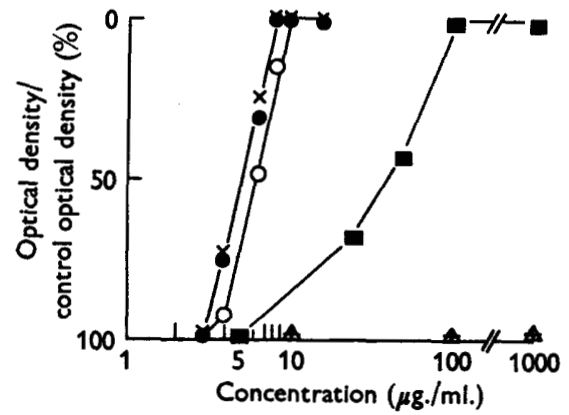

Fig. 1

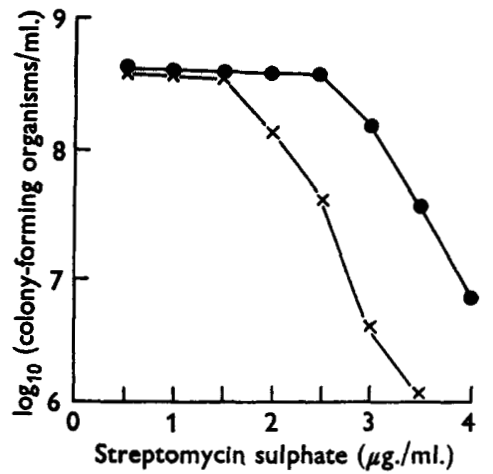

Fig. 2

Fig. 1. Inhibition of growth, expressed as optical density as $\%$ of control optical density, in cultures incubated for $16 \mathrm{hr}$. and containing streptomycin sulphate (O); dihydrostreptomycin sulphate $(x)$; mannosidostreptomycin sulphate $(O)$; streptidine sulphate $(\triangle)$; streptomycinic acid sulphate $(+)$ (all aerobic); streptomycin sulphate (anaerobic) (घ); at the indicated concentration.

Fig. 2. The numbers of colonies produced by identical samples taken from a growing culture, on plates containing streptomycin at the indicated concentration. Plates incubated aerobically $(x)$ or anaerobically $(0)$.

Distribution of sensitivity to streptomycin. In growing cultures of the type used for subsequent experiments, it was found that there was a considerable variation in the sensitivity of different organisms to streptomycin, as measured by the number of organisms able to form colonies on agar containing streptomycin at different concentrations (Fig. 2).

Effects of streptomycin on growing cultures. In initial experiments the effect of streptomycin on growth was followed by measurements of the optical density of cultures. It was found that the factor relating optical density to bacterial dry weight/ml. of culture is the same in streptomycin-inhibited organisms as in normal organisms, and since no major changes occur in the ratios of the major constituents. 
of organisms following inhibition by streptomycin, optical density measurements were considered to be a reliable method of following the increase in cell constituents during inhibition of growth by streptomycin.

The effects of a range of concentrations of streptomycin on increase of optical density of growing cultures are shown in Fig. 3A; Fig. 3B shows the changes which occurred in the numbers of colony-forming organisms in the same cultures. In cultures growing anaerobically (under nitrogen), the rate of loss of viability was reduced; at lower concentrations of streptomycin this rate was almost zero and at higher concentrations it was still lower than the corresponding rate under aerobic conditions (Fig. 3B).

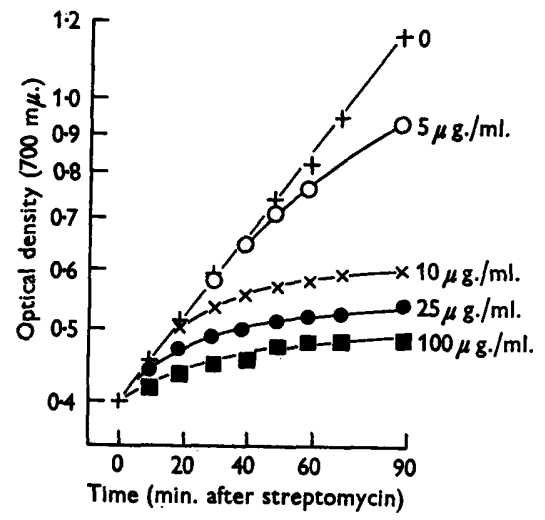

A

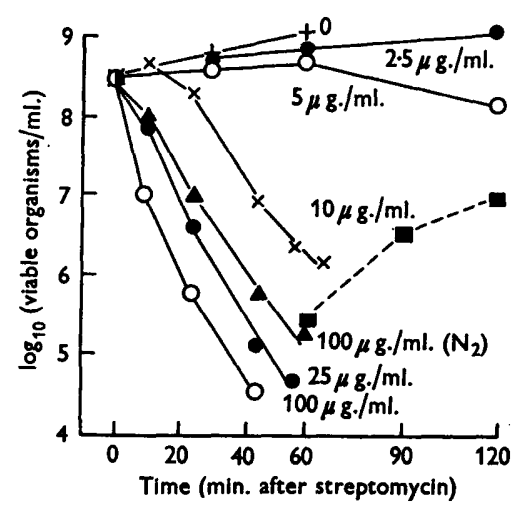

B

Fig. 3. Optical density and numbers of colony-forming organisms in growing cultures after addition of streptomycin sulphate to the indicated final concentration. Each concentration of streptomycin represents a separate experiment. A, Optical density; $B$, colony-forming organisms. The curve labelled $\left(\mathrm{N}_{2}\right)$ at $100 \mu \mathrm{g}$. streptomycin/ml. represents an experiment under anaerobic conditions. The points joined by dashed lines represent the number of organisms in the culture containing $10 \mu \mathrm{g}$. streptomycin sulphate/ml. which were able to produce colonies on plates containing $10 \mu \mathrm{g}$. streptomycin sulphate/ml., multiplied by $10^{3}$.

If the initial $\mathrm{pH}$ of the growth medium was adjusted to values lower than that $(7 \cdot 2)$ used normally, the rate of development of inhibition of growth was less on addition of streptomycin (Fig. 4). The pH value of the medium normally used did not change during the exponential phase of growth.

Effects of streptomycin on non-growing organisms. If organisms were harvested from a growing culture when the optical density $(700 \mathrm{~m} \mu)$ reached $0 \cdot 4$, and resuspended at the same culture density in growth medium containing streptomycin sulphate (10 $\mu \mathrm{g} . / \mathrm{ml}$.) for $75 \mathrm{~min}$., no further growth occurred on resuspension in fresh growth medium, as would be anticipated as after this period of contact with streptomycin only c. $\mathbf{0 . 1} \%$ of the organisms are viable (Fig. 3B). After this time there was a slow increase in optical density which may have been due to growth of a few streptomycin-resistant organisms, since there was an increase in the number of such organisms during this period (Fig. 3B). When, in similar experiments, the organisms were exposed to streptomycin for the same period either in growth medium cooled in an ice bath to $5^{\circ}$, or in medium which contained no nitrogen 
Table 2. Effect of conditions of exposure to streptomycin on rate of loss of viability

Samples taken from a growing culture were incubated with streptomycin in an experiment similar to that in Fig. 5 .

\begin{tabular}{|c|c|c|c|c|c|}
\hline \multirow[b]{3}{*}{ Experiment } & \multirow[b]{3}{*}{ Conditions } & \multicolumn{4}{|c|}{ Viable organisms/ml. } \\
\hline & & \multirow[b]{2}{*}{ Zero time } & \multicolumn{3}{|c|}{$\begin{array}{c}\text { After } 60 \mathrm{~min} .+ \text { streptomycin sulphate } \\
\text { at }(\mu \mathrm{g} . / \mathrm{ml} .)\end{array}$} \\
\hline & & & $\mathbf{0}$ & 10 & 25 \\
\hline \multirow[t]{3}{*}{1} & $\begin{array}{l}\text { Growth medium, } 37^{\circ} \text {, } \\
\text { air }\end{array}$ & $2.2 \times 10^{0}$ & $6.8 \times 10^{9}$ & $2.2 \times 10^{6}$ & $2.3 \times 10^{5}$ \\
\hline & $\begin{array}{l}\text { Growth medium, } 87^{\circ} \text {, } \\
\text { nitrogen }\end{array}$ & $2.2 \times 10^{9}$ & $4.8 \times 10^{9}$ & $4.2 \times 10^{\circ}$ & $2.0 \times 10^{2}$ \\
\hline & Growth medium, $5^{\circ}$, air & $2.2 \times 10^{9}$ & $2.9 \times 10^{9}$ & $2.8 \times 10^{9}$ & $\mathbf{2 . 8} \times 10^{8}$ \\
\hline \multirow[t]{2}{*}{$\mathbf{2}$} & Growth medium, $\mathbf{3 7} 7^{\circ}$ & $1.2 \times 10^{9}$ & 一 & $9.8 \times 10^{7}$ & $1.2 \times 10^{5}$ \\
\hline & $\begin{array}{l}\text { Growth medium, } 37^{\circ}, \\
\text { air, + chloramphenicol } \\
(100 \mu \mathrm{g} . / \mathrm{ml} .)\end{array}$ & $1.2 \times 10^{\circ}$ & 一 & $9.9 \times 10^{8}$ & $4.8 \times 10^{8}$ \\
\hline $\mathbf{3}$ & $\begin{array}{l}\text { Growth medium with- } \\
\text { out peptone, } 37^{\circ} \text {, air }\end{array}$ & $5 \cdot 1 \times 10^{3}$ & - & $4.8 \times 10^{8}$ & $5.7 \times 10^{8}$ \\
\hline
\end{tabular}

source, growth was immediately resumed on resuspension in fresh growth medium (Fig. 5). The numbers of viable organisms found after exposure to streptomycin under these various conditions are shown in Table 2. It was also found (Table 2) that if chloramphenicol $(100 \mu \mathrm{g} . / \mathrm{ml}$.) is added to growing organisms simultaneously with streptomycin, loss of viability is prevented. Under these conditions, therefore, it appears that streptomycin is not bactericidal to Staphylococcus aureus in the absence of some process associated with growth of the organisms.

Reversal of action of streptomycin by streptomycin derivatives. Although streptidine sulphate is without detectable growth-inhibiting effect (Fig. 1), it was found that, at high concentrations relative to streptomycin, this compound can partially reverse the effect of streptomycin on growth (Fig. 6). This effect was not due to the addition of sulphate. ions, since addition of the same quantity of $\left(\mathrm{NH}_{4}\right)_{2} \mathrm{SO}_{4}$ did not affect the activity of streptomycin. In similar experiments streptomycinic acid sulphate, at concentrations up to $1 \mathrm{mg}$. $/ \mathrm{ml}$., produced only a very small reversal of the inhibition of growth by streptomycin sulphate $(25 \mu \mathrm{g} . / \mathrm{ml}$.$) .$

Synthesis of cell constituents during inhibition of growth by streptomycin. In the following experiments, cultures were divided when the optical density reached $0 \cdot 3-0 \cdot 4$, and streptomycin was added to one portion; radioactive compounds, when used were added to the culture at the time of inoculation.

Figure $7 \mathrm{~A}$ shows progress curves of the incorporation of ${ }^{14} \mathrm{C}-\mathrm{L}$-glutamic acid into the major cell fractions. To facilitate comparisons of the subsequent increases, the curves have been adjusted to coincide at the time of addition of streptomycin. A similar experiment using ${ }^{14} \mathrm{C}-\mathrm{L}$-alanine, and in which incorporation of radioactivity into the hot-TCA-soluble fraction was used as a measure of synthesis of teichoic acid, as suggested by Park \& Hancock (1960), is shown in Fig. 7 B. It appears from these experiments that the rates of incorporation of these precursors into all the major cell fractions are reduced in a parallel manner during the period of development of growth inhibition by streptomycin. 


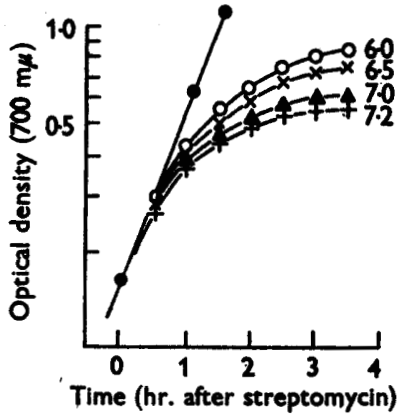

Fig. 4

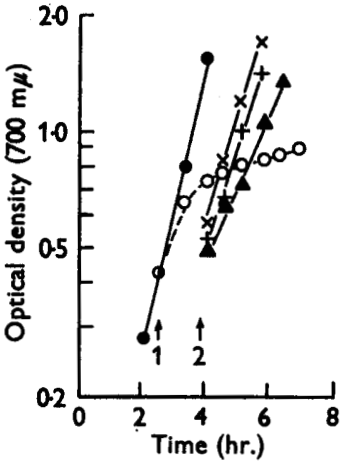

Fig. 5

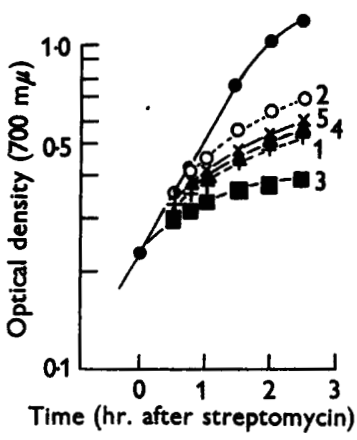

Fig. 6

Fig. 4. Optical density changes after addition of streptomycin sulphate $(10 \mu \mathrm{g} . / \mathrm{ml}$. to cultures growing in media adjusted to the indicated initial $\mathrm{pH}$ values; (O) control.

Fig. 5. Optical density changes after resuspension of streptomycin-treated organisms in fresh growth medium. At 1, the organisms were harvested and suspended in the following medium with addition of streptomycin sulphate $(10 \mu \mathrm{g} . / \mathrm{ml}$.): (O), growth medium, $87^{\circ}$, in air; $(x)$, as 1 but in nitrogen; $(+)$, as 1 but at $5^{\circ} ;(\Lambda)$, growth medium without peptone, $37^{\circ}$, in air. After $75 \mathrm{~min}$., at 2 , the organisms were filtered and resuspended in fresh growth medium at $37^{\circ}$. Controls (O).

Fig. 6. The effect of simultaneous addition of streptidine sulphate on the optical density changes following addition of streptomycin sulphate. Controls $(O)$. The final concentrations ( $\mu \mathrm{g} . / \mathrm{ml}$.$) were$

$\begin{array}{ccr}\text { Curve } & \begin{array}{c}\text { Streptomycin } \\ \text { sulphate }\end{array} & \begin{array}{r}\text { Streptid } \\ \text { sulphat }\end{array} \\ \mathbf{1} & \mathbf{2 5} & \mathbf{0} \\ \mathbf{2} & \mathbf{2 5} & \mathbf{2 5 0} \\ \mathbf{3} & \mathbf{5 0} & \mathbf{0} \\ \mathbf{4} & \mathbf{5 0} & \mathbf{2 5 0} \\ \mathbf{5} & \mathbf{5 0} & \mathbf{5 0 0}\end{array}$

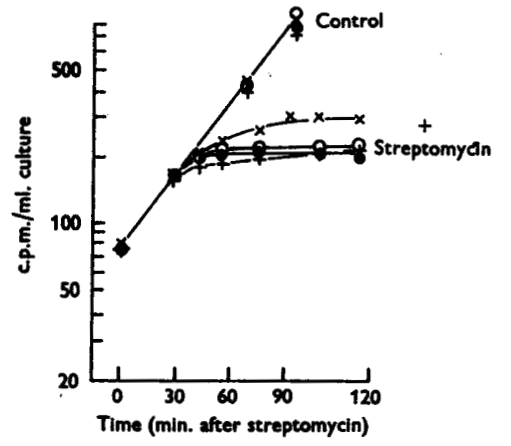

$\mathbf{A}$

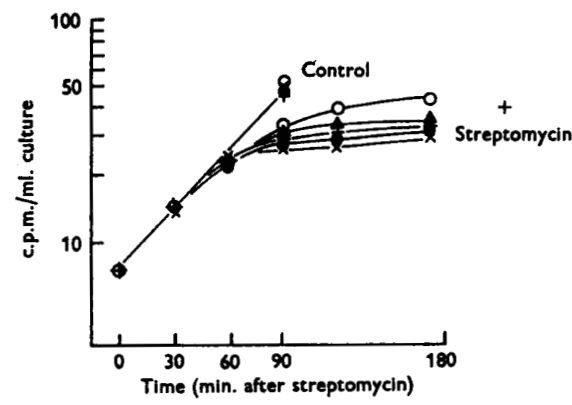

$\mathbf{B}$

Fig. 7. Incorporation of ${ }^{14} \mathrm{C}-\mathrm{L}$-glutamic acid (A) and ${ }^{14} \mathrm{C}-\mathrm{L}-\mathrm{alanine}(\mathrm{B})$ into some major cell fractions after addition of streptomycin sulphate $(10 \mu \mathrm{g} . / \mathrm{ml}$.). The values have been adjusted to coincide at the time of addition of streptomycin; the units on the ordinate represent the observed radioactivities multiplied by the following factors: Cold-TCA soluble fraction (O): $A, \times 1.83 ; B, \times 2.38$. Ethanol soluble fraction $(\times): A, \times 75.0$; B, $\times$ 5.90. Hot-TCA soluble fraction $(A): B, \times 1 \cdot 89$. Protein $(+): A, \times 2 \cdot 63 ; B, \times 0 \cdot 71$. Cell-wall mucopeptide (O): A, $\times 10 \cdot 0 ; \mathrm{B}, \times 1 \cdot 0$. 
Determinations of the nucleic acid content of a culture after addition of streptomycin (Fig. 8) showed that the rates of synthesis of both TNA and DNA are also reduced simultaneously with the rate of incorporation of ${ }^{14} \mathrm{C}$-L-proline into the protein fraction.

Table 3. Quantities of some compounds in hot-water extracts from normal and streptomycin-inhibited organisms

Values in parentheses are from a separate experiment.

\begin{tabular}{|c|c|c|c|c|}
\hline - & \multirow{2}{*}{$\begin{array}{c}\text { Total } \\
\text { amino acids } \\
(\mu \mathrm{mole} / \mathrm{g} . \text { cells })\end{array}$} & \multirow[b]{2}{*}{$\begin{array}{l}\text { Optical density } \\
(260 \mathrm{~m} \mu) / \mathrm{g} \text {. cells }\end{array}$} & \multicolumn{2}{|c|}{$\begin{array}{c}\text { Phosphate } \\
\text { ( } \mu \text { mole/g. cells) }\end{array}$} \\
\hline & & & Inorganic & Total \\
\hline Control organisms & $451(476)$ & $1380(1280)$ & 171 & 625 \\
\hline $\begin{array}{l}\text { Organisms grown with } \\
\text { streptomycin sulphate } \\
(25 \mu \mathrm{g} . / \mathrm{ml} .) \text { for } 60 \mathrm{~min} .\end{array}$ & $518(512)$ & $1220(1350)$ & 182 & 582 \\
\hline
\end{tabular}

There appears therefore to be no specific or differential inhibition by streptomycin of the synthesis of any major constituent of growing organisms, such as occurs with the antibiotics chloramphenicol (Harrington, 1958; Mandelstam \& Rogers, 1958) and with penicillin (Park, 1958).

The experiments using ${ }^{14} \mathrm{C}$-amino acids (Figs. 7 $\mathrm{A}$ and $\mathrm{B}$ ) also suggest that there is no accumulation of amino acids in the metabolic pool during the period of inhibition of growth. This finding was confirmed by direct determinations of the total amino acid pool (Table 3). It was also found (Table 3) that during this time there were no large changes in the amounts of $260 \mathrm{~m} \mu$-absorbing substances or of inorganic phosphate in the metabolic pool. Separation of the pool amino acids by paper chromatography showed no detectable alterations in the relative amounts of each amino acid in the pool. These results suggest that the rates of synthesis, or of uptake into the organisms, of compounds in the metabolic pool decrease simultaneously with the rates of incorporation of these compounds into cell material.

Effect of streptomycin on incorporation of ${ }^{32} \mathrm{P}$. Figure 9 shows progress curves of incorporation of radioactivity into the major fractions of the cold-TCA-soluble fraction, and into the cold-TCA-insoluble fraction, of organisms growing in the presence and absence of streptomycin, when ${ }^{32} \mathrm{P}$-orthophosphate was added at the same time as streptomycin. In one similar experiment, organisms were harvested after $60 \mathrm{~min}$. and the cold-TCA-soluble fraction was fractionated by the procedure used by Umbreit (1953); Table 4 shows the radioactivity found in the fractions obtained by this procedure.

Glucose metabolism by organisms grown in the presence of streptomycin. The foregoing experiments suggested that none of the major biosynthetic processes which were investigated are specifically inhibited during the period in which growth becomes inhibited by streptomycin. It seemed that these findings would be compatible with the existence of an early effect of streptomycin on reactions concerned with supply of metabolic energy. Since the breakdown of glucose is the major source of metabolic energy under the conditions of growth used here, attention was directed to the etabolism of glucose during the period of inhibition of growth by streptomycin. It was found that organisms harvested from cultures growing in the 
presence of streptomycin had significantly lower $Q_{0}$ values than organisms from parallel control cultures. Figure $10 \mathrm{~A}$ shows $Q_{0_{2}}$ (glucose) values of organisms harvested at successive times following addition of streptomycin; the increase in optical density, and incorporation of ${ }^{14} \mathrm{C}-\mathrm{L}$-proline into protein, in the same cultures are included in Fig. 10A for comparison. The decrease in $Q_{o_{2}}$ (glucose) value was apparently not due solely to a dilution of the population of normal organisms by organisms with impaired respiration, since at higher concentrations of streptomycin the $Q_{0_{0}}$ value also decreased when expressed relative to a unit volume of culture (Fig. 10B). Some variation was found from time to time in the magnitude of the

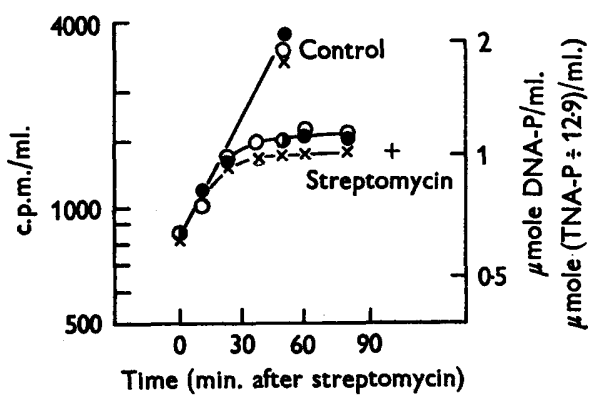

Fig. 8

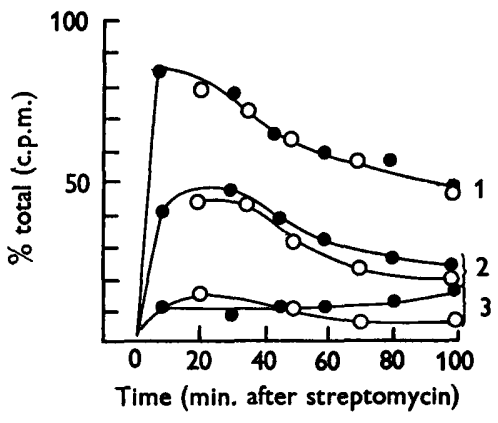

Fig. 9

Fig. 8. Synthesis of total nucleic acid (TNA) (O) and deoxyribonucleic acid (DNA) (O); and incorporation of ${ }^{11} \mathrm{C}-\mathrm{L}$-proline into protein $(x)$, after addition of streptomycin sulphate (10 $\mu \mathrm{g} . / \mathrm{ml}$.).

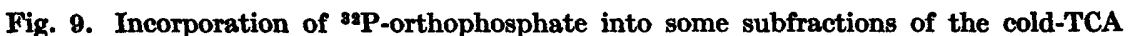
soluble fraction in a control culture $(O)$ and after addition of streptomycin sulphate $(10 \mu \mathrm{g} . / \mathrm{ml}$.) (O), expressed as \% of the total radioactivity in the cells. Curve 1 : total cold-TCA soluble fraction. Curve 2: barium-insoluble fraction. Curve 3: bariumsoluble, ethanol-insoluble fraction.

Table 4. Effect of streptomycin on incorporation of ${ }^{32} \mathbf{P}$ into some components of the cold-TCA soluble fraction

\begin{tabular}{|c|c|c|c|c|c|}
\hline & & & adioactivity & unts/min.) in & \\
\hline & $\begin{array}{l}\text { Increase } \\
\text { in dry } \\
\text { weight } \\
\text { (mg./ml./hr.) }\end{array}$ & $\begin{array}{c}\text { Intact } \\
\text { organisms }\end{array}$ & $\begin{array}{c}\text { Cold-TCA } \\
\text { soluble } \\
\text { fraction }\end{array}$ & $\begin{array}{c}\text { Cold-TCA } \\
\text { soluble } \\
\text { fraction } \\
\text { (organic } \\
\text { phosphates) }\end{array}$ & $\begin{array}{c}\text { Fraction } \\
\text { containing } \\
\text { 'new com- } \\
\text { pound' of } \\
\text { Umbreit } \\
\text { (1953) } \\
\text { (organic } \\
\text { phosphates) }\end{array}$ \\
\hline $\begin{array}{l}\text { Control organisms } \\
\text { (C) }\end{array}$ & 0.50 & 128,700 & 99,980 & 68,700 & 1,225 \\
\hline $\begin{array}{l}\text { Organisms grown } \\
\text { with streptomycin } \\
\text { sulphate (25 } \mu \mathrm{g} \cdot / \\
\text { ml.) for } 60 \mathrm{~min} . \text { (S) }\end{array}$ & 0.34 & 96,800 & 70,370 & 48,400 & 990 \\
\hline S, $\% \mathbf{C}$ & $68 \cdot 0$ & $75 \cdot 4$ & $70 \cdot 4$ & 70.5 & $80 \cdot 9$ \\
\hline
\end{tabular}


changes in $Q_{o_{2}}$ (glucose) following addition of streptomycin; Table 5 shows results from two experiments to indicate the range of this variation. It is clear from Fig. $10 \mathrm{~A}$, however, that a decrease in $Q_{0_{2}}$ value occurs before the rate of synthesis of cell material begins to decrease, and that the depression of $Q_{\mathrm{o}_{2}}$ value is considerable by the time that inhibition of growth becomes complete.

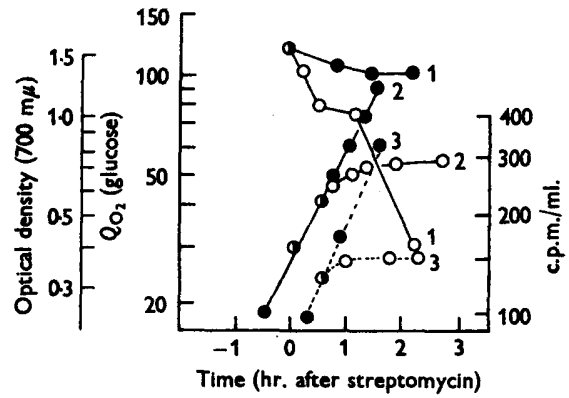

A

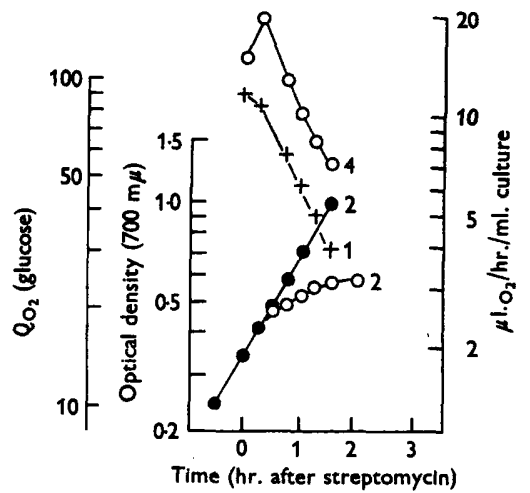

B

Fig. 10. $Q_{0}$ (glucose) values (curves 1) of organisms harvested from control cultures (O) and from cultures after addition of streptomycin (O). A. Streptomycin sulphate $25 \mu \mathrm{g} . / \mathrm{ml}$. Values of the optical density of the cultures (curves 2), and of the incorporation of ${ }^{14} \mathrm{C}-\mathrm{L}$-proline into the protein fraction (curves 3 ) are included for comparison. B. Streptomycin sulphate concentration $50 \mu \mathrm{g} . / \mathrm{ml}$. Curve $1\left(Q_{\mathrm{O}_{2}}\right.$ glucose) from culture after the addition of streptomycin $(+)$. Curve 4 represents the rate of glucose oxidation of harvested organisms expressed relative to a unit volume of culture.

To investigate the metabolism of glucose by routes other than the EmbdenMeyerhof pathway, the production of ${ }^{14} \mathrm{CO}_{2}$ from ${ }^{1-14} \mathrm{C}$-glucose $\left(1-\mathrm{CO}_{2}\right),{ }^{6-}{ }^{14} \mathrm{C}$ glucose $\left(6-\mathrm{CO}_{2}\right)$ and generally-14 $\mathrm{C}$-labelled-glucose $\left(\mathrm{CO}_{2}\right)$ was investigated in normal organisms and organisms growing in the presence of streptomycin, with the results shown in Table 6. The interpretation of experiments of this type has been discussed by Heath \& Koffler (1956), who have shown how the ratio of the quantities of 1- $\mathrm{CO}_{2}$ to $6-\mathrm{CO}_{2}$ can be related to the proportion of the total glucose oxidized which is metabolized via pathways in which $C_{1}$ of glucose is preferentially oxidized, such as the pentose phosphate cycle. In the presence of streptomycin there appears to

Table 5. $Q_{\mathrm{O}_{2}}$ (glucose) of organisms after growth in the presence of streptomycin at varying concentrations

Results of two experiments ( $30 \mathrm{~min}$ and $60 \mathrm{~min}$ ) chosen to show the variation observed in the magnitude of the reduction of $Q_{\mathrm{O}_{2}}$ values in streptomycin-inhibited organisms.

Concentration of streptomycin sulphate ( $\mu \mathrm{g} \cdot / \mathrm{ml}$.

$\boldsymbol{Q}_{\mathrm{O}_{\mathrm{g}}}$ (glucose) of streptomycininhibited organisms, as $\%$ of that of control organisms, after growth in the presence of streptomycin for

$\begin{array}{cc}30 \text { min. } & 60 \text { min } \\ 64 & 92 \\ 42 & 69 \\ 40 & 49 \\ 35 & 45 \\ 29 & 39\end{array}$


be no significant difference in the very small production of $6-\mathrm{CO}_{2}$ (which may indicate a very low level of cyclic operation of the tricarboxylic acid cycle in this organism), or in the proportion of glucose metabolized via a $\mathrm{C}_{\mathbf{1}}$-specific oxidation.

Table 6. Production of ${ }^{14} \mathrm{CO}_{2}$ from generally- and specifically- ${ }^{14} \mathrm{C}$-labelled glucoses during growth in presence and absence of streptomycin

Cultures growing in manometer flasks; the specific activity of ${ }^{14} \mathrm{C}$-glucose was the same in each culture.

Radioactivity (counts/min.) in $\mathrm{CO}_{2}$, as $\%$ of that in $\mathrm{CO}_{2}$ from generally-14C-labelled glucose, produced from

\begin{tabular}{|c|c|c|c|c|c|}
\hline & & & & & \\
\hline & & & -glucose & 6.1 & glucose \\
\hline Experiment & $\begin{array}{l}\text { Sample } \\
\text { time } \\
\text { (min.) }\end{array}$ & $\begin{array}{l}\text { Control } \\
\text { culture }\end{array}$ & $\begin{array}{c}\text { +Streptomycin } \\
\text { sulphate } \\
\text { (25 } \mu \mathrm{g} . / \mathrm{ml} .)\end{array}$ & $\begin{array}{l}\text { Control } \\
\text { culture }\end{array}$ & $\begin{array}{c}\text { + Streptomycin } \\
\text { sulphate } \\
\text { (25 } \mu \mathrm{g} \cdot / \mathrm{ml} .)\end{array}$ \\
\hline 1 & $\begin{array}{l}80 \\
60\end{array}$ & $\begin{array}{l}22 \cdot 2 \\
14 \cdot 3\end{array}$ & $\begin{array}{l}18 \cdot 2 \\
14 \cdot 5\end{array}$ & $\begin{array}{l}1 \cdot 3 \\
0.9\end{array}$ & $\begin{array}{l}0.9 \\
0.7\end{array}$ \\
\hline 2 & $\begin{array}{l}15 \\
45\end{array}$ & $\begin{array}{l}15 \cdot 5 \\
15 \cdot 5\end{array}$ & $\begin{array}{l}14 \cdot 2 \\
17 \cdot 0\end{array}$ & $\begin{array}{l}0.9 \\
1.0\end{array}$ & $\begin{array}{l}0.8 \\
0.8\end{array}$ \\
\hline
\end{tabular}

Oxidation of other substrates by organisms grown in the presence of streptomycin. It was of interest to investigate if organisms grown in the presence of streptomycin have a lower oxidative activity towards other substrates as well as towards glucose. The only substrates which this strain of Staphylococcus aureus was found to be capable of oxidizing at significant rates were glucose, lactate, glycerol, and formate. $Q_{0_{2}}$ values obtained in two experiments for oxidation of these substrates by organisms harvested after growth in the presence of streptomycin and by organisms grown in parallel control cultures are given in Table 7, which also includes similar results using dihydrostreptomycin. In these experiments the organisms were harvested when growth inhibition was first detectable. The addition of streptomycin

Table 7. $Q_{\mathrm{o}_{2}}$ values of normal and streptomycin-inhibited organisms

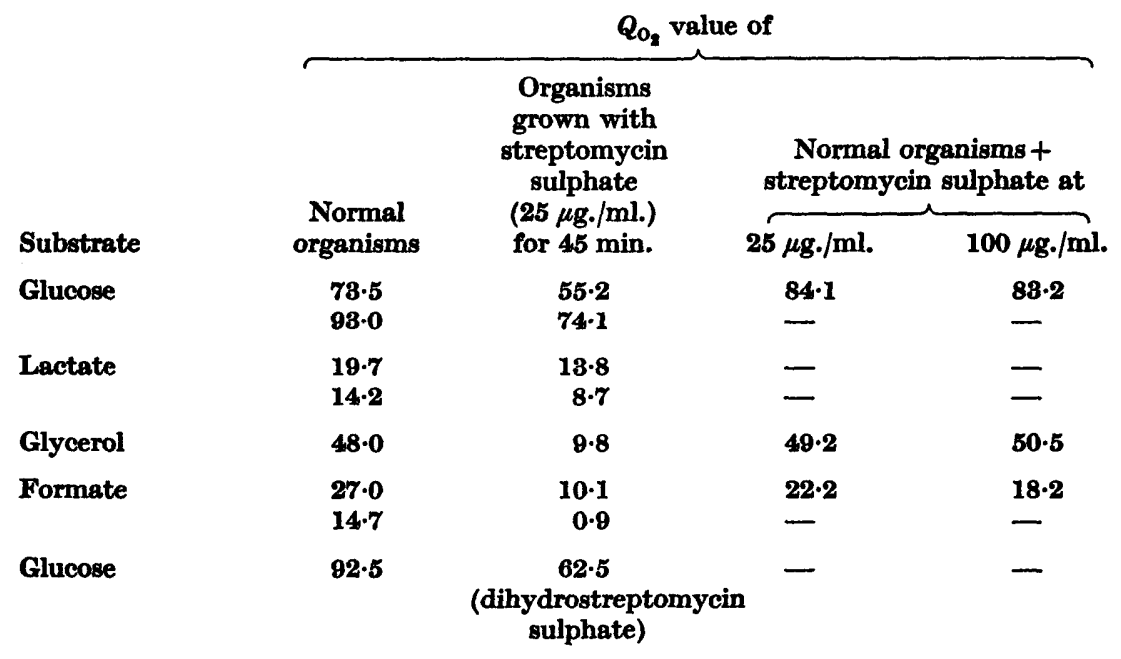


sulphate, at concentrations up to $1 \mathrm{mg} . / \mathrm{ml}$, to the contents of the manometer flask resulted in no depression of the $Q_{\mathrm{o}_{2}}$ values of normal organisms.

Specificity of reduction of oxidation rates. It was important to determine if the reduced $Q_{\mathrm{O}_{2}}$ values of streptomycin-inhibited organisms were due to a specific effect of streptomycin, or were merely a consequence of reduction in the growth rate. $Q_{\mathrm{O}_{2}}$ values of organisms whose growth had been inhibited by other antibiotics, or by cooling, were therefore determined, with the results shown in Table 8. The growth rates of the cultures in these experiments were reduced to zero when the

Table 8. Effect of inhibition of growth on $Q_{\mathrm{o}_{\mathbf{g}}}$ values

Organisms harvested $60 \mathrm{~min}$. after addition of antibiotics or after transfer of the culture to the refrigerator.

Growth of culture inhibited by

\section{- (control)}

Penicillin (10 units/ml.)

Chloramphenicol (50 $\mu \mathrm{g} . / \mathrm{ml}$.)

Aureomycin hydrochloride (10 $\mu \mathrm{g} . / \mathrm{ml}$.)

Streptomycin sulphate $(25 \mu \mathrm{g} . / \mathrm{ml}$.)

Cooling

$\overbrace{\text { Glucose }}^{Q_{\mathbf{O}_{2}} \text { values of organisms on }} \begin{array}{cc}\text { Formate } \\ 104 \cdot 8 & 51 \cdot 6 \\ 102 \cdot 2 & 42 \cdot 5 \\ 100 \cdot 8 & 42 \cdot 5 \\ 103 \cdot 2 & 51 \cdot 0 \\ 68 \cdot 5 & 18 \cdot 4 \\ 122 \cdot 2 & 52 \cdot 0\end{array}$

organisms were harvested, with the exception of the cultures containing chloramphenicol and aureomycin. In these cultures, increases in optical density and in dry weight of organisms occur due to synthesis of cell-wall material (Hancock \& Park, 1958; Park, 1958), but since there is no increase in cellular protein the $Q_{0_{2}}$ values for these cultures were calculated relative to the dry weight of organisms at the time of addition of the antibiotics. The reduction in $Q_{\mathrm{O}_{2}}$ values appears to be specific to organisms whose growth has been inhibited by streptomycin.

\section{DISCUSSION}

Although the experiments reported here on factors affecting the activity of streptomycin were not intended to be comprehensive or exhaustive, but only to establish a basis for biochemical work, they show a number of characteristics of the bactericidal action of this antibiotic on Staphylococcus aureus which are important in considering possible modes of action of streptomycin. It has been frequently demonstrated (for review see Lightbown, 1957) that, as found here, the activity of streptomycin against facultatively anaerobic organisms is less when growth occurs anaerobically, and this may be related to the very low activity of streptomycin against many obligatory anaerobic organisms. We are not aware of any previously published observations which show that the bactericidal action of streptomycin on growing organisms can be prevented if growth is arrested during contact with streptomycin, as appears to be the case with $S$. aureus; however, while this paper was in preparation, Anand \& Davis (1960) reported that streptomycin is not bactericidal to Escherichia, coli in the presence of chloramphenicol. In some instances in which organisms lose viability only under conditions in which growth can occur, it has been shown that 'unbalanced synthesis' of some component of the organism may be responsible (for review see Roberts, McQuillen \& Roberts, 1959). If such 
a process occurs in $S$. aureus in the presence of streptomycin, it does not apparently involve 'unbalanced synthesis' of any of the major cell constituents which have been investigated here.

The concentrations of streptomycin which have been used in these experiments are higher than the minimum inhibitory concentration determined by a conventional test (Table 1). The results in Fig. $\mathbf{3 A}$ show that no effect of streptomycin at concentrations below $5 \mu \mathrm{g}$. streptomycin sulphate/ml, can be observed on growth during the exponential phase under the conditions used here; nevertheless, the organisms do lose viability at these low concentrations of streptomycin but at a very low rate (Fig. B B). It was convenient to carry out biochemical experiments over a reasonably short period of time, and the concentration of streptomycin used here was chosen to enable this to be done while still allowing a reasonable period in which to search for biochemical changes before growth became inhibited. The observed time lag which occurs before inhibition of growth becomes complete could be due to a number of possible factors, including the period taken for streptomycin to reach its site of action, or the time taken to utilize preformed precursors in a metabolic pathway blocked by streptomycin.

Although no large changes were found in the distribution of ${ }^{32} \mathbf{P}$ in the major fractions of the cold-TCA-soluble fraction in organisms grown in the presence of streptomycin, these results, together with those showing no change in the total amount of $260 \mathrm{~m} \mu$-absorbing material in this fraction, are regarded as only preliminary attempts to investigate any changes in these fractions. The possibility remains that redistributions occur in the individual components in these fractions although the total quantities are unchanged, and it is difficult to draw conclusions until more detailed results are obtained. The ${ }^{32} \mathrm{P}$-labelled compounds which occur in the fractions obtained from Staphylococcus aureus using the fractionation procedure of Umbreit (1958) have not been identified, but no inhibition by streptomycin could be detected of incorporation of ${ }^{32} \mathrm{P}$ into that fraction into which such incorporation is inhibited by streptomycin in Escherichia coli (Umbreit, 1958). It is possible that inhibition of incorporation of ${ }^{32} \mathrm{P}$ into a minor component of this fraction would be difficult to detect if large amounts of other compounds were present. Similarly, although there is no large change in the total quantity of $260 \mathrm{~m} \mu$ absorbing compounds in hot-water extracts of organisms grown in the presence of streptomycin, changes in the quantities of individual compounds in this fraction have been detected in preliminary separations by ion-exchange chromatography using the procedure of Hurlbert, Schmitz, Brumm \& Potter (1954). We have found no evidence of leakage of compounds from the metabolic pool of organisms growing in the presence of streptomycin, as has been reported to occur in E. coli (Anand \& Davis, 1960).

The earliest biochemical change which we have been able to detect is the reduced ability of organisms grown in the presence of streptomycin to oxidize glucose and other substrates. Jackson (1958) has described experiments similar in some respects to those reported here, in which growing cultures of Staphylococcus aureus were exposed to dihydrostreptomycin. In this case it was also found that organisms harvested from such cultures have lower rates of oxidation of glucose and succinate than normal organisms; succinate oxidation was found to be depressed to a greater extent than glucose oxidation. Oxidation of glucose and pyruvate by cultures of 
Shigella sonnei is also reduced when streptomycin, at concentrations which inhibit increase in cell material, is present in the growth medium (Henry, Housewright \& Berkman, 1949).

It would be anticipated that a reduced ability to oxidize glucose would be reflected as a reduction in the rate of metabolism of glucose by organisms during growth in the presence of streptomycin. Experiments in which the pathways of glucose metabolism by this strain of Staphylococcus aureus have been investigated, using specifically-14 $\mathrm{C}$-labelled glucoses, will be described in a further paper, but some observations on the effect of streptomycin are of interest. ${ }^{14} \mathrm{C}$-Glucose was added to a culture at the same time as streptomycin, and hot-water extracts were prepared from the organisms as soon as inhibition of growth could be detected; the radioactive compounds in these extracts were separated by paper chromatography. The differences observed between control and streptomycin-treated organisms showed that, in the presence of streptomycin, relatively more radioactivity occurred in intermediates of the Embden-Meyerhof pathway, and relatively less in metabolic end-products, indicating that there is a reduction in the rate at which glucose is metabolized via this pathway. However, if organisms grown in the presence of streptomycin were allowed to metabolize ${ }^{14} \mathrm{C}$-glucose to completion, the final distribution of ${ }^{14} \mathrm{C}$ among the products did not differ from that produced by normal organisms.

The reduced $Q_{\mathrm{o}_{2}}$ values of streptomycin-inhibited organisms do not appear to be a consequence of inhibition of growth, in so far as they are not observed in organisms whose growth has been inhibited by other means. When inhibition of growth by streptomycin is first detectable, the reduction in rate of glucose oxidation is not large, and the possibility that it is a cause of growth inhibition must remain open; it is possible that these early changes are consequences of yet an earlier effect of streptomycin. However, there does appear to be some correlation between the growth rate at any time after addition of streptomycin and the $Q_{\mathrm{o}_{2}}$ (glucose) values of organisms harvested at that time. The reductions in $Q_{0_{2}}$ values for other substrates are greater than that for glucose, and these changes suggest that in organisms grown in the presence of streptomycin there could be a metabolic block in some reaction common to the metabolism of all these substrates. Since the $Q_{\mathrm{O}_{2}}$ value for formate oxidation is reduced in streptomycin-inhibited organisms, and since the tricarboxylic acid cycle operates only to a very small extent in this organism (as shown by the rate of production of ${ }^{14} \mathrm{CO}_{2}$ from ${ }^{6-14} \mathrm{C}$-glucose), it is possible that this block is in the chain of respiratory enzymes; this possibility is being investigated further.

I am much indebted to Dr H. B. Woodruff, of Merck, Sharpe and Dohme Research Laboratories, for gifts of mannosidostreptomycin and streptidine; to Mr R. Grasham, of the Distillers Co. Ltd., for a gift of streptomycinic acid; to Mr F. McManus for technical assistance; and to Mr J. Dempsey for permission to use some unpublished results included in Fig. 2. 


\section{REFERENCES}

Anand, N. \& Davis, B. D. (1960). Damage by streptomyein to the cell membrane of Escherichia coli. Nature, Lond. 185, 22.

BARER, G. R. (1951). The action of streptomycin on Bacterium lactis aerogenes. J. gen. Microbiol. 5, 1.

Barkulis, I. L. (1953). Inhibition of the anaerobic pyruvate metabolism of Escherichia coli by dihydrostreptomycin. J. Bact. 65, 337 .

Bondi, A., Dietz, C. C. \& Spaulding, E. H. (1946). Interference with the antibacterial action of streptomycin by reducing agents. Science, 103, 399.

Burton, K. (1956). A study of the conditions and mechanism of the diphenylamine reaction for colorimetric estimation of DNA. Biochem. J. 62, 315.

Cocking, E. C. \& Yemm, E. W. (1955). The determination of amino acids with ninhydrin. Analyst, 80, 209.

Fiske, C. H. \& SubbaRow, Y. (1925). The colorimetric determination of phosphorus. J. biol. Chem. 66, 375.

GaLe, E. F. \& TAYLOR, E. S. (1947). The assimilation of amino acids by bacteria. 5. The action of penicillin in preventing the assimilation of glutamic acid by Staphylococcus aureus. J. gen. Microbiol. 1, 314.

Gale, E. F. \& Folkes, J. P. (1953). The assimilation of amino acids by bacteria. 14. Nucleic acid and protein synthesis in Staphylococcus aureus. Biochem. J. 53, 483.

HaNCOCK, R. (1960). Some early biochemical changes accompanying the inhibition by streptomycin of the growth of Staphylococcus aureus. Biochem. J. 74, $12 P$.

Hancock, R. \& Park, J. T. (1958). Cell wall synthesis by Staphylococcus aureus in the presence of chloramphenicol. Nature, Lond. 181, 1050.

Harrington, M. G. (1958). The action of chloramphenicol on protein and nucleic acid synthesis by Escherichia coli strain B. J. gen. Microbiol. 18, 767.

Heath, E. C. \& Koffler, H. (1956). Biochemistry of filamentous fungi. Quantitative significance of an oxidative pathway during the growth of Penicillium chrysogenum. J. Bact. 71, 174.

HENRY, R. J. \& HobBy, G. L. (1949). The mode of action of streptomycin. In Streptomycin, Ed. S. A. Waksman. London: Ballière, Tindall and Cox.

Henry, R. J., Housewright, R. D. \& Berkman, S. (1949). Studies on streptomycin. 6. The effects of streptomycin on the metabolism of multiplying bacteria. J. Bact. 57, 447.

Hurlaert, R. B., Schmitz, H., Brumm, A. F. \& Potter, V. R. (1954). Nucleotide metabolism. 3. Chromatographic separation of acid-soluble nucleotides. J. biol. Chem. 209, 23.

JACKson, F. L. (1958). Streptomycin and bacterial respiration. Nature, Lond. 181, 281.

LightBown, J. W. (1954). An antagonist of streptomycin and dihydrostreptomycin produced by Pseudomonas aeruginosa. J. gen. Microbiol. 11, 477.

Lightвown, J. W. (1957). Metabolic processes underlying streptomycin resistance. G. ital. Chimioter. 4, 22.

Lightbown, J. W. \& JACkson, F. L. (1956). Inhibition of cytochrome systems of heart muscle and certain bacteria by the antagonists of dihydrostreptomycin: 2-alkyl-4hydroxyquinoline N-oxides. Biochem. J. 63, 130.

MANDElstaM, J. \& Rogers, H. J. (1958). Chloramphenicol-resistant incorporation of amino acids into Staphylococci and cell wall synthesis. Nature, Lond. 181, 956.

MaY, J. R., Voureka, A. E. \& Fleming, A. (1947). Some problems in the titration of streptomycin. Brit. med. J. i, 627.

Mrues, A. A. \& Mrsra, S. S. (1938). The estimation of the bactericidal power of the blood. J. Hyg., Camb. 38, 732.

PARK, J. T. (1958). Inhibition of cell-wall synthesis in Staphylococcus aureus by chemicals which cause accumulation of wall precursors. Biochem. J. 70, 2 P.

Park, J. T. \& Hancock, R. (1960). A fractionation procedure for studies of the synthesis of cell wall mucopeptide and of other polymers in cells of Staphylococcus aureus. J. gen. Microbiol. 22, 249. 
Roberts, R. B., McQurllen, K. \& Roberts, I. Z. (1959). Biosynthetic aspects of metabolism. Annu. Rev. Microbiol. 13, 1.

Rosanoff, E. I. \& Sevag, M. G. (1953). Alternate metabolic pathways in streptomycin sensitive and resistant strains of Escherichia coli. Antibiot. et Chemother. 3, 495.

UMBREIT, W. W. (1853). The action of streptomycin. VI. A new metabolic intermediate. J. Bact. 66, 74.

Umbreit, W. W., Burris, R. H. \& Stauffer, J. F. (1951). Manometric Techniques in Tissue Metabolism. Minneapolis, U.S.A.: Burgess Publishing Co.

Vignais, P. \& Vignais, P. (1954). Sur l'oxydation de l'acetate par Escherichia coli. Variations en fonction de la croissance. Rôle inhibiteur de la streptomycine. C.R. Acad. Sci., Paris, 238, 2127.

Waksman, S. A. (1949). Historical introduction. In Streptomycin, Ed. S. A. Waksman. London: Baillière, Tindall and Cox.

Wasserman, A. E., Lessner, J. M. \& West, M. K. (1954). Reversal of the streptomycin injury of Escherichia coli. J. gen. Physiol. 38, 213. 